\title{
A política das plazas nacionales e a atribuição de ofícios públicos na Catalunha após a Guerra de Sucessão: Uma desnaturalização da administração.
}

\author{
Alberto Airton Amendola Gandolfo *
}

DOI: 10.11606/issn.2318-8855.v9i1p349-369

Resumo: Este artigo analisará a atribuição de ofícios públicos no Principado da Catalunha após a Guerra de Sucessão (1701-1714), sobretudo, os métodos utilizados para a escolha de servidores dos ofícios públicos no contexto de reorganização da administração pública na Monarquia espanhola. Nosso objetivo é estudar as políticas utilizadas para essas escolhas, em especial, a política das plazas nacionales, que assegurava que uma parte mínima dos cargos indicados fosse conferida a catalães. Tais medidas foram implementadas na conjuntura que se constrói após a promulgação da Nueva Planta em 1716 por Felipe V, que extinguiu a maioria dos foros do Principado, dentre os quais destacamos as prohibiciones de estrangería, que garantiam a exclusividade dos cargos públicos aos catalães. Para atingir o objetivo proposto, discutiremos a bibliografia sobre esse assunto, em especial, recorrendo aos estudos especializados dos historiadores Pere Molas i Ribalta (1942-X) e Jean Pierre Dedieu (1948-X), mapeando as divergências e convergências de perspectiva sobre o tema em questão. Trata-se de um artigo de recenseamento bibliográfico e portanto, suas conclusões serão embasadas na interpretação e contraposição dos trabalhos e das estatísticas prosopográficas mobilizadas pelos autores.

Palavras-chave: História da Catalunha, Ofícios públicos no Antigo Regime, Nova Planta espanhola.

\footnotetext{
* Sobre o autor: Alberto Airton Amendola Gandolfo, graduando em História pela FFLCH - USP, com interesse majoritário nas áreas de História Moderna, História Ibérica, Administração colonial na América e Administração pública no Antigo Regime. E-mail para contato: alberto.gandolfo@usp.br.
} 


\section{artigos}

\section{Alberto Airton Amendola Gandolfo}

A questão da naturalidade dos funcionários públicos se mostra um tema relevante do período moderno da Monarquia Hispânica, principalmente por conta da constante resistência dos antigos reinos da Coroa de Aragão em aceitar a presença de funcionários e soldados "estrangeiros", que ocorria desde a união junto a Coroa de Castela em 1479, o fenômeno é destacado pelo célebre Pierre Vilar (1975, p.34.). Essa rejeição fez com que a Monarquia espanhola dispusesse de diversos esforços para controlar a atribuição de cargos nesses domínios ao longo dos séculos.

Para compreender, portanto, como o processo de mudança nas atribuições de ofícios públicos na Catalunha é realizado, faz-se necessário entender o funcionamento anterior à Nueva Planta e os ataques realizados por Madrid para modificá-lo. A insaculación, como era denominada a maneira catalã de atribuição de cargos, consistia em um método no qual os postulantes aos cargos, obrigatoriamente catalães, tinham seus nomes escritos em pedaços de papéis que eram então misturados e sorteados. Esta forma de eleição, entretanto, fora ameaçada diversas vezes pelo governo Habsburgo, inicialmente por Felipe II no final do século XVI e também após o fim da rebelião catalã de 1640, mas ainda assim os sorteios foram mantidos, mesmo que modificados. A temática explorada com afinco pelo notável historiador da Universidad de Barcelona Josep María Torras i Ribé (1993; 1996).

No século XVIII, contudo, o advento da Guerra de Sucessão ${ }^{1}(1701-1714)$ e a oposição aberta da maior parte dos nobres de Valência, Catalunha e Aragão ao pretendente Bourbon, acentuaram as tensões e a subsquente ocupação militar dessas províncias resulta na promulgação da Nueva Planta. O decreto procurou alterar o ordenamento jurídico dos antigos reinos e criar uma administração consonante com a

\footnotetext{
${ }^{1}$ Conflito armado entre a dinastia Habsburgo, que então reinava a Espanha, e os Bourbon, que clamavam o trono após a morte de Carlos II sem herdeiros.
} 


\section{artigos}

A política das plazas nacionales e a atribuição de ofícios públicos na Catalunha após a Guerra de Sucessão: Uma desnaturalização da administração.

exercida em Castela, em uma clara busca por uma maior centralização, espelhada nos Bourbon franceses.

A extinção da insaculación como método de atribuição de ofícios na Catalunha só acontece, portanto, com a instauração da Nueva Planta no Principado em janeiro de 1716, após os Tratados de Utrecht (1713-1715) que marcam a derrota da oposição catalã na Guerra de Sucessão e confirmam a mudança dinástica. O decreto transformara então a maior parte dos ofícios administrativos do Principado em cargos de indicação real, e os que não, eram atribuídos pelos funcionários indicados pelo Rei, o que criou diversas tensões sociais no Principado, sobretudo na elite política. Uma das maiores problemáticas causadas pela mudança estava ligada às origens desse novo corpo de funcionários, apesar do emprego da política de plazas nacionales que asseguraria uma fatia mínima de cargos a catalães, acerca da qual nos ocuparemos mais ao longo do texto.

Os historiadores selecionados para elucidar a problemática proposta se valem metodologicamente da História Social da Administração, especialmente, da reconstituição prosopográfica em seus trabalhos; essa técnica consiste em uma investigação e levantamento de biografias (nesse caso de agentes da administração pública na Catalunha), sobre as quais estes historiadores traçam padrões, argumentos e retiram estatísticas. Dentre esses dados, os que mais nos interessam são os relacionados à naturalidade dos funcionários estudados, o que demonstraria a dimensão da importância do local de nascimento para uma carreira de funcionalismo público no Principado durante o século XVIII.

Cabe ressaltar antes ainda, a importância das recentes publicações da historiadora María del Mar Felices De la Fuente $(2011$, 2016), da Universidad de Almería, 


\section{artigos}

\section{Alberto Airton Amendola Gandolfo}

sobre a ocupação e indicação de cargos públicos durante o reinado de Felipe V (17001746), assim como o interessante trabalho de Marcelo Luzzi Traficante (2015) da Universidad Autónoma de Madrid, que renovam o interesse sobre a temática aqui abordada e demonstram sua atualidade para a historiografia produzida na Espanha, mesmo que o artigo esteja centrado sobre autores mais clássicos.

Nossa ênfase central será colocada sobre os escritos de Pere Molas i Ribalta (1942-X) e Jean Pierre Dedieu (1948-X) e sua relação, construída por meio da problemática. O primeiro, historiador doutorado pela Universidad de Barcelona em 1970 se especializa inicialmente na questão dos grêmios barceloneses do século XVIII, ao longo de sua carreira Molas amplia seu escopo investigativo e trata da naturalidade dos funcionários públicos da Catalunha em diversos órgãos, assim como estuda a política de plazas nacionales. O segundo, discípulo do hispanista francês Bartolomé Benassar na Université de Toulouse, notório pelos estudos hispânicos na França, teceu análises sobre os gobernadores das principais cidades catalãs durante o século XVIII e através deste estudo com o uso da prosopografia, procurou demonstrar que o peso do local de nascimento nas escolhas dos magistrados era menos importante do que outros fatores, como a proximidade junto à família real. Para nós, o principal objetivo é desenvolver os antagonismos e aproximações presentes nos escritos desses autores, analisando as obras pertinentes de cada um e enfatizando os argumentos de suas posições, acionando ainda outros trabalhos que se demonstrem importantes para elucidar a problemática estudada.

A começar por Molas i Ribalta, (1980) o historiador inicia seu estudo pelo enquadramento metodológico utilizado, a prosopografia e suas fontes, as biografias coletivas, aludindo então aos diversos trabalhos que utilizam do método na época em que escreve. Molas destaca o papel da historiografia britânica para a inserção e 


\section{artigos}

A política das plazas nacionales e a atribuição de ofícios públicos na Catalunha após a Guerra de Sucessão: Uma desnaturalização da administração.

teorização da prosopografia no meio acadêmico, não deixando de citar os trabalhos em desenvolvimento na Alemanha e na França. O autor faz essa introdução para destacar a maior dificuldade e escassez de documentos no panorama espanhol, obrigando a realização de estudos menos abrangentes, porém valiosos em sua perspectiva, citando os exemplos de Manuel Tuñón de Lara e Diego Mateo.

Após essa primeira parte dedicada a uma introdução metodológica, Molas nos apresenta seu foco de estudo, as Audiencias bourbônicas, órgãos encarregados sobretudo pela administração de justiça nos territórios espanhóis do século XVIII. Ao colocar em perspectiva a administração pública no período, Molas o distancia da divisão de poderes do estado liberal e demonstra como essa esteve por muito tempo íntimamente ligada ao exercício da justiça e sua administração seria o principal dever do monarca na Idade Moderna. Compara então as Audiencias com os Consejos que tinham sob sua jurisprudência sobretudo funções macro judiciais, enfatizando que na conjuntura prévia a Nueva Planta os dois órgãos tinham funções semelhantes no aparato estatal.

Molas destaca então a gradual diminuição nas responsabilidades processuais pessoais do monarca em instancias judiciais e administrativas. No caso castelhano, o processo teria se consolidado sob o domínio dos Reis Católicos e na Coroa de Aragão ainda durante o século XVI. Ao detalhar o processo, o historiador ressalta, entretanto, que mesmo no século XVIII a responsabilidade dos órgãos administrativos regionais ainda era escassa, visto que o Consejo Real controlava diretamente as tratativas legais através dos corregidores.

Com a Guerra de Sucessão, contudo, a administração pública nos antigos reinos aragoneses muda completamente, tanto nos quadros dos homens públicos quanto na 


\section{artigos}

\section{Alberto Airton Amendola Gandolfo}

própria estrutura de governo. Com a vitória parcial austracista no início da guerra, há uma expulsão da maior parte dos funcionários públicos em exercício, que depois é revertida parcialmente mas ainda causa instabilidade. Após o fim do conflito, contudo, a consolidada vitória Bourbon e a consequente instauração da Nueva Planta extinguem a antiga conjuntura. O propósito de Felipe $\mathrm{V}$, disserta o historiador era que os reinos da Coroa de Aragão se governassem como em Castela, sem diferença. Aludindo então a Mercader Riba (1917-1989), Molas enfatiza que as grandes diferenças nos governos, enquanto a administração castelhana tinha alcançado um grau altamente civilista e letrado, o novo método imposto à Coroa de Aragão era fortemente militarizado.

Após detalhar o novo funcionamento institucional das Audiencias sob a estrutura bourbônica, Molas trata da questão sociológica por trás dos orgãos e dos funcionários públicos do caso valenciano e catalão. Ao discutir a estabilidade dos cargos, o historiador divide o século XVIII em quatro períodos: o primeiro, até 1720 de frequentes mudanças, causadas pelas repercussões das operações militares ainda em andamento; o segundo, de grande estabilidade entre 1720 e 1760; o terceiro, entre 1760 e 1770, marcado por uma mobilidade nos cargos e o quarto de total instabilidade a partir de 1789.

A partir dessa periodização, Molas introduz os cargos dos funcionários públicos estudados, os denominando como burocratas civis, grupo que englobaria os regentes, oidores, alcades del crimen y fiscales. Após essa especificação, Molas afirma que com o fim das prohibiciones de estrangería através da Nueva Planta, um dos objetivos da Monarquia, para além da implementação das instituições de Castela, foi a introdução de um corpo de funcionários provenientes daquela Coroa. Apesar desse claro objetivo na tese do historiador, essa não era uma inovação que podia aplicar-se de maneira indiscriminada, muito menos total. Desse modo, todas as Audiencias reservaram na 


\section{artigos}

A política das plazas nacionales e a atribuição de ofícios públicos na Catalunha após a Guerra de Sucessão: Uma desnaturalização da administração.

prática uma parte de seus cargos a homens naturais do território local, eram as chamadas plazas nacionales, política que foi alvo de numerosas reflexões, tanto no Consejo de Castilla, órgão maior da administração Bourbon do século XVIII, como nos setores dirigentes dos territórios aragoneses, que nunca deixaram de reclamar por uma maior participação de naturais em seus governos. A política das plazas nacionales, ressalta Molas, nunca teve uma normativa clara, e a Monarquia bourbônica seguiu a direção de assegurar inicialmente uma posição de ligeira maioria em favor de castelhanos, mas mesmo com a estabilização da situação pós-guerra, Madrid se negou a regulamentar a política.

Para o caso catalão, durante a etapa interina entre 1714 e 1716, a administração local ficou primariamente nas mãos de apoiadores de Felipe $V$ naturais do Principado, os chamados botijlers. Após a instauração do decreto de 1716 e as pressões por parte de aliados durante a Guerra de Sucessão por medidas punitivas aos que se opuseram a Felipe $V$, o papel desses catalães na administração pública diminui, e mesmo que figuras importantes no entorno do rei e até mesmo o Consejo de Castilla tenham se posicionado a favor da indicação de uma proporção significativa de naturais nos cargos da Audiencia catalã, um número fixo nunca foi definido, causando uma marginalização desses na administração pública como um todo.

De volta a Audiencia e em especial a seleção dos candidatos àquelas vagas, Molas discorre sobre o organismo encarregado por selecionar os candidatos das Audiencias, o Gímm de Castilla. Sobre esse, inicia sua exposição referindo-se à significante ausência de naturais de Aragão, somente quatro ao longo do século e em épocas distintas. Afirma então que durante a primeira metade do setecentos, a política seguida foi de impedir abertamente um predomínio de naturais nos cargos administrativos em geral. 


\section{artigos}

\section{Alberto Airton Amendola Gandolfo}

Para conservar essa maioria, o secretário de estado, extrajudicialmente, devia advertir o monarca caso a indicação de qualquer grupo reinícola aragonês superasse o número de castelhanos em determinada função, comprovando essa afirmação através do uso de cartas de secretários de estado.

Para reforçar essa política, as consultas para cobrir cargos entre 1720-1730 tinham instruções específicas para a proporção entre castelhanos e naturais, demonstrando o cuidado da monarquia em evitar os possíveis inconvenientes que um maior número de reinícolas aragoneses causaria nos órgãos administrativos. Tal agenda fica clara, quando o historiador cita o caso da escolha de um oídor em 1747, após a morte do catalão Ignacio Rius y Bruniquer, Molas explicita a interferência direta do rei, que deu ordens claras para a não escolha de outro catalão, considerando que a proporção em relação aos castelhanos se tornaria desfavorável.

Não obstante, Molas enfatiza que todas as Audiencias contavam com um número de juízes nascidos no reino, os quais estariam familiarizados com os foros, privilégios e costumes locais. A indicação desses cargos atendia a uma necessidade pragmática; na Catalunha não se acabaram com todos os foros locais, restando majoritariamente a legislação individual, que atendia a crimes e processos entre súditos de classes mais baixas, e essa assim como os precedentes processuais se encontravam majoritariamente escritos no idioma local, não dominado pelos funcionários castelhanos.

Para comparar as proporções de funcionários locais nas Audiencias aragonesas, Molas apoia-se num informe de 1799, no qual Madrid limitava a três os postos civis reservados a naturais na Audiencia de Saragoça, o que quando comparado as biografias dos funcionários das outras Audiencias demonstraria uma porcentagem maior da presença local nessa Audiencia, mais fraca na Catalunha e em Maiorca e quase nula em 


\section{artigos}

\section{A política das plazas nacionales e a atribuição de ofícios públicos na Catalunha} após a Guerra de Sucessão: Uma desnaturalização da administração.

Valência. O historiador destaca, contudo, que a problemática foi objeto de preocupação e reivindicação dos grupos dirigentes dos domínios ao decorrer de todo o século XVIII, sublinhando os apelos ao monarca de 1748 e 1760 que pediam pela diminuição da dramática desigualdade entre naturais e castelhanos nos órgãos regionais, já que esses continuavam com uma presença muito escassa nos órgãos administrativos fora da Catalunha. O período de exceção, ou melhor representatividade local, acontecera quando o castelhano Conde de $\operatorname{Aranda}^{2}$ (1719-1798) fez parte da liderença do corpo administrativo de Aragão, e através de sua autoridade e diversas ações legais aumentou a proporção de naturais na administração pública aragonesa entre 1765 e 1766.

Aranda teria defendido, segundo Molas, a atribuição de postos no Consejo de Castilla a aragoneses naturais e não castelhanos que já tinham trabalhado naquelas Audiencias, visto que já ter exercido função pública naquelas regiões era utilizado como argumento de que esses funcionários poderiam representar as demandas daqueles povos. Durante 1766 e 1773, quando Aranda presidiu o Consejo, foram nomeados um catalão e um valenciano como conselheiros no órgão nacional, aumentando também a proporção de Valencianos e catalães nas Audiencias locais, como nunca antes.

Após tratar de cada cargo em específico, demonstrando a manutenção do padrão de maioria absoluta de castelhanos, com exceção dos alcades del crimen (cargos mais técnicos que necessitavam do domínio da língua local), Molas ressalta a exclusão da análise dos regentes e dos fiscales, que em princípio teriam sido vedadas a naturais, com raras exceções, sob o argumento de que essas posições de "chefia" e "vigia" não

\footnotetext{
${ }^{2}$ Figura importantíssima do reformismo ilustrado espanhol no século XVIII, o Conde fora ainda secretário de Estado de Carlos IV em 1792.
} 


\section{artigos}

\section{Alberto Airton Amendola Gandolfo}

deveriam ser ocupadas por funcionários que tivessem uma relação sentimental com o território em que exerciam sua função.

O historiador aborda então as trajetórias dos funcionários estudados dentro do aparato estatal da Monarquia espanhola, destacando o fato de que muitos naturais, apesar da frequente mobilidade de funções e localidades típicas da época, optavam por permanecer em suas terras natais, detalhadamente, pouquíssimos funcionários das Ilhas Baleares saíam dali, enquanto alguns catalães e aragoneses saiam e valencianos tinham maior facilidade para fazê-lo. Cabe destacar que essa mobilidade se dava majoritariamente através de promoções. No esquema reproduzido abaixo, (1980, p. 92) Molas sublinha a maior quantidade de funcionários naturais da localidade que permanecem naqueles cargos por mais de 15 anos.

\section{Cuadro I. Duración del cargo superior a 15 años.}

\begin{tabular}{|l|l|l|l|l|}
\hline & Aragón & Cataluña & Valencia & Mallorca \\
\hline Naturales & 18 & 18 & 12 & 8 \\
\hline Foráneos & 10 & 11 & 21 & 4 \\
\hline & Más de 30 años & De 25 a 30 & De 20 a 25 & De 15 a 20 \\
\hline & nat. for. & nat. for. & nat. for. & nat. for. \\
\hline Aragón & 41 & $4 \times$ & 53 & 56 \\
\hline Cataluña & 42 & 62 & 22 & 65 \\
\hline Valencia & 22 & 12 & 44 & 514 \\
\hline
\end{tabular}




\section{artigos}

\section{A política das plazas nacionales e a atribuição de ofícios públicos na Catalunha}

após a Guerra de Sucessão: Uma desnaturalização da administração.

Após tratar especificamente dos cargos estudados sob a ótica das promoções, com maior detalhe, Molas finaliza seu escrito exemplificando os pontos levantados através do exemplo de uma família aragonesa apoiadora de Felipe V durante a Guerra de Sucessão que esteve presente na administração Bourbon durante três gerações durante o século XVIII, os "Ric", naturais de Fonz.

Já sobre Dedieu (2000) e sua tese central sobre os gobernadores das principais cidades catalãs, o mesmo inicia seu escrito pela introdução da questão da proporção entre militares e civis nos cargos, a Catalunha pós Guerra de Sucessão é transformada pela Monarquia espanhola em local de residência para um corpo permanente do exército espanhol, e isso, assim como a vontade de manter uma força repressiva no aparato estatal catalão, fez com que grande parte dos ofícios públicos fossem designados a militares, o assunto é abordado com maior detalhe no trabalho de Gloria Franco Rubio (1997). A partir dessa problemática inicial, o historiador desenvolve a questão dos requisitos para a atribuição de cargos a partir das indicações reais, enfatizando o peso que a proximidade junto à família real tinha nessas escolhas.

Com essa argumentação, Dedieu caminha para a construção de sua hipótese, de que previamente a eleição desses funcionários existia um forte vínculo pessoal entre os gobernadores e os círculos mais próximos ao monarca, selecionando para comprovar essa tese os governos de Barcelona, Gerona e Lérida. Para embasar seu estudo, o historiador estabelece uma lista de homens públicos que exercem o cargo entre 1715 e 1808, reconstituindo suas biografias a modo prosopográfico e determinando as conexões sociais através da documentação e do que deduziu de suas carreiras. Ressalta, entretanto, que a maioria das biografias analisadas era composta por funcionários que construíram uma carreira no aparato estatal, mudando 


\section{artigos}

\section{Alberto Airton Amendola Gandolfo}

constantemente de localidade, em contraste com a sensação de permanência vitalícia encontrada em autores anteriores.

Ao referenciar o apêndice do escrito, Dedieu afirma que é notório, com a exceção de alguns casos interinos e outros de funcionários que tenham morrido precocemente ou de acontecimentos políticos imprevistos, que os principais postos territoriais permanecem sob o controle de um número limitado de pessoas seletas. Ao desenvolver tal afirmação, o autor ressalta que a capacidade profissional e o favor constante e especialmente intenso da monarquia são os fatores mais importantes para a conquista e manutenção dos postos estudados. Ao abordar os militares dentro dessa conjuntura, Dedieu salienta que os cargos de maior importância estariam limitados a um subgrupo dentro da liderança do exército. A temática é também explorada por Franco Rubio (2005), que coloca em perspectiva a criação nesse momento histórico de uma nova classe de funcionários estatais militares.

Voltando ao assunto central, Dedieu argumenta sobre a importância do local de nascimento dos funcionários utilizando do prisma naturalidade-vassalagem como opostos, no qual a figura do soberano e da comunidade de nascimento são distintas e de interesses contrários. Em um período dominado pelas movimentações absolutistas nas monarquias europeias, os soberanos espanhóis tentaram há tempos (como já vimos) romper com o freio que os foros locais impunham a sua autoridade e rebaixar desse modo o papel da naturalidade reforçando a vassalagem, objetivo obtido com a Nueva Planta nos antigos reinos aragoneses. Para o estudioso francês, o objetivo de Madrid não era trocar a naturalidade dos funcionários públicos de um domínio para o outro e sim de escolhe-los de maneira livre, reforçando a sua autoridade e a força de vassalagem nesses territórios. Dedieu exemplifica sua hipótese através das indicações 


\section{artigos}

A política das plazas nacionales e a atribuição de ofícios públicos na Catalunha após a Guerra de Sucessão: Uma desnaturalização da administração.

de Felipe V, o qual não buscou abrir aos castelhanos os postos antes reservados a catalães, mas sim a seus prediletos, independente da procedência.

O historiador toma o cuidado, contudo, de tratar as áreas do direito local como uma exceção nos planos da Monarquia, destacando que na administração de justiça em níveis inferiores e também superiores, a atribuição de cargos priorizaria reinícolas ou até mesmo naturais das próprias zonas em que exerceriam suas atividades, algo evidenciado também por Molas, de maneira mais detalhada, por conta dos conhecimentos linguísticos necessários. Nas esferas que tradicionalmente já estariam sob incumbência do soberano, entretanto, como na administração militar, Felipe V teria imposto o exercício livre de sua vontade, sem se restringir a fronteiras internas e até mesmo externas à Espanha. Um trabalho que o historiador cita para embasar sua tese de que a Monarquia espanhola age na administração de justiça valorizando a naturalidade é de Cerro Nargánez, (1998) sobre os alcades mayores nomeados na Catalunha pelos reis Bourbon.

Retornando a obra do hispanista francês, ao tratar diretamente da relação quantitativa entre catalães/castelhanos de gobernadores, Dedieu nos apresenta o seguinte quadro em seu estudo (2000, p. 494), representado abaixo:

Cuadro II. Origen territorial de 10 gobernadores propietarios de Barcelona, Gerona y Lérida, 1714-1808 (años de permanencia en el puesto).

\begin{tabular}{|l|l|l|l|l|l|}
\hline & Desconocido & Castilla & Norte & Aragón/Cataluña & No regnicolas \\
\hline
\end{tabular}




\section{artigos}

Alberto Airton Amendola Gandolfo

\begin{tabular}{|c|c|c|c|c|c|}
\hline Barcelc & & & & & \\
\hline $\begin{array}{l}1714- \\
1760\end{array}$ & 10 (21\%) & 26 (58\%) & $x$ & $10(21 \%)$ & $x$ \\
\hline $\begin{array}{l}1761- \\
1808\end{array}$ & 0 & $8(17 \%)$ & 7 (14\%) & $1(2 \%)$ & $32(67 \%)$ \\
\hline Geron & & & & & \\
\hline $\begin{array}{l}1714- \\
1760\end{array}$ & 0 & $3(6 \%)$ & 0 & $27(58 \%)$ & $17(36 \%)$ \\
\hline $\begin{array}{l}1761- \\
1808\end{array}$ & $1(2 \%)$ & 0 & $13(27 \%)$ & $12(25 \%)$ & $22(46 \%)$ \\
\hline Lérida: & & & & & \\
\hline $\begin{array}{l}\text { 1714- } \\
1760\end{array}$ & $12(26 \%)$ & 0 & 0 & $4(9 \%)$ & $31(65 \%)$ \\
\hline $\begin{array}{l}1761- \\
1808\end{array}$ & $10(21)$ & $2(4 \%)$ & $16(33 \%)$ & $3(6 \%)$ & $17(36 \%)$ \\
\hline Total & 35 (11\%) & $39(14 \%)$ & $36(13 \%)$ & $47(16 \%)$ & $130(46 \%)$ \\
\hline
\end{tabular}

Sobre esses dados afirma enfaticamente que, mesmo que todos os funcionários de naturalidade desconhecida fossem castelhanos, esses teriam uma posição muito inferior quando comparados em perspectiva aos naturais das localidade estudadas. 


\section{artigos}

\section{A política das plazas nacionales e a atribuição de ofícios públicos na Catalunha após a Guerra de Sucessão: Uma desnaturalização da administração.}

Desse modo, matematicamente afirma que havia mais possibilidades estatísticas de um catalão chegar a esses cargos do que um castelhano.

Dedieu surpreende-se com a grande quantidade catalães e aragoneses no quadro público, pensando na oposição desses reinos à Castela na Guerra de Sucessão, salientando que valencianos e baleares não tiveram cargo algum, o que seria mais esperado visto a postura punitiva de Madrid. Outro parentêses que o historiador faz é em relação aos governadores de procedência não catalã, que tinham antes ou estabeleceram durante seu mandato laços familiares com a sociedade catalã, geralmente através do matrimônio.

Com o foco novamente sobre o grupo catalão/aragonês, Dedieu afirma que todos os homens naturais desses domínios a ocuparem os cargos estudados provinham de famílias que apoiaram sem reservas Felipe $\vee$ durante a Guerra de Sucessão, colhendo os frutos dessa decisão ao decorrer de todo o século XVIII. Há, entretanto, uma exceção, que o historiador atribui à fidelidade pessoal de José de Córdoba Alagón, que havia feito parte do corpo administrativo, mesmo que seu irmão, o conde de Sástago, tenha desempenhado um papel importante junto ao grupo austracista na guerra. Sobre as famílias a ocuparem cargos na administração pública Bourbon, Dedieu faz um breve apanhado sobre características gerais, e as coloca em grupos: o primeiro e principal de famílias dominantes da nobreza, seja a nível local, regional ou nacional. O segundo grupo consistia das famílias de comerciantes, mais ligadas ao comércio internacional ou interterritorial, menos fixadas a um ou outro domínio da Coroa. Um terceiro grupo estaria tão vinculado à família real que seus interesses fundamentalmente consistiam de defender e aumentar o poderio monárquico. Afirma então que generalizando esse esquema e o projetando 


\section{artigos}

\section{Alberto Airton Amendola Gandolfo}

geograficamente sobre as origens dos funcionários e as biografias levantadas, o grupo dominante no conjunto de gobernadores seria o último, cerca de 3/4 dos gobernadores estudados, calculando em anos de permanência nos postos.

Com essa primeira argumentação o hispanista francês demonstra sua tese de maneira objetiva, afirmando que a proximidade junto a família real, seja via familiar ou pessoal era indispensável na obtenção de cargos. A prova decisiva como assim denomina o autor, viria dos funcionários castelhanos, os quais teriam todos uma relação de grande proximidade com a Monarquia, demonstrável através das fontes, antes de suas nomeações.

Dedieu então aprofunda a discussão acerca das famílias castelhanas a serviço real e destaca como vão estabelecendo laços matrimoniais com outras famílias integrantes do aparato administrativo espanhol, se desvinculando de suas raízes até se tornarem completamente uma nobreza de serviço, grupo social de nobres completamente centrado na corte e no favor ao rei, ocupando considerável parte do aparato público, diluindo assim uma naturalidade definida. Sobre os detentores de cargos na corte entre os gobernadores ou em seus círculos familiares diretos, as concessões de títulos de Castela, ou as honrarias variadas atribuídas a esses homens públicos, não traça nenhuma argumentação específica, ressalta, entretanto, a ausência das maiores famílias da aristocracia castelhana entre o quadro de gobernadores catalães. Cabe sublinhar que Dedieu afirma que a vinculação com a família real não é tão intensa em todas as esferas do serviço público, os membros das Audiencias e os corregidores que se recrutavam através da Cámara de Castilla, não tinham contato tão próximo com o soberano quanto os gobernadores, nem mesmo através de suas famílias. 


\section{artigos}

\section{A política das plazas nacionales e a atribuição de ofícios públicos na Catalunha após a Guerra de Sucessão: Uma desnaturalização da administração.}

No fechamento do estudo, o autor indica uma conclusão surpreendente poe meio dos dados levantados, principalmente acerca do seleto grupo de pessoas que controlava os postos mais importantes de mando militar/territorial administrativo. Reafirmando que a característica principal para a atribuição a esses ofícios seria a relação com a figura real e há uma relativa desvinculação com o meio de origem. Outra conclusão retirada é que o grupo social tende a se organizar em uma nobreza de serviço, fechada sobre si mesma, se isolando de alguma maneira do restante da sociedade. Com pouquíssimas exceções, a vasta maioria desses gobernadores era militar e havia desempenhado atividades notórias no decorrer de suas carreiras, e suas origens eram variadas e não importantes para a ocupação dos cargos.

Colocando em contraposição as ideias dos principais autores no artigo abordados identificamos em seus estudos, pontos de aproximação e de distanciamento que enfatizaremos em nossa conclusão. Cabe ressaltar, que apesar dos focos investigativos serem diferentes, um se debruça mais sobre a administração de justiça e o outro sobre a militar, por muitas vezes ambos trabalham e tecem argumentos sobre a conjuntura geral da administração pública espanhola, ampliando e diminuindo os escopos de análise conforme constroem suas argumentações e são nesses momentos que a relação entre as teses fica mais clara.

A começar pelas áreas em que se acercam, os dois autores têm uma hipótese muito semelhante sobre o destino dos funcionários/famílias que apoiaram os Bourbon na Guerra de Sucessão. Mesmo que Molas explore alguns casos nos quais os funcionários aragoneses que apoiaram a dinastia vencedora percam seu posto prévio após a guerra, praticamente todos são recompensados posteriormente e constantemente ao decorrer do século. Também possuem concordâncias sobre a 


\section{artigos}

\section{Alberto Airton Amendola Gandolfo}

importância militar no aparato administrativo do século XVIII, até mesmo no âmbito da justiça, sendo essa uma das características marcantes da administração pública espanhola no período pós 1714.

Os pontos de divergência, por sua vez, estão situados principalmente sobre a importância do local de nascimento na atribuição dos cargos e o papel que o monarca exerce sobre essas indicações. Tratando do contexto geral de atribuição, para Dedieu, a Monarquia espanhola não visava substituir um corpo de funcionários catalães por um castelhano, Molas por outro lado, afirma explicitamente que esse era um dos objetivos Bourbon. Um destaque usado por Dedieu para corroborar com a hipótese de que os castelhanos eram minoria, foi demonstrar que a maioria desses e de outros estrangeiros a ocuparem cargos no Principado se envolveram com famílias locais através do matrimônio, algo que contrasta com a ideia de uma elite de serviço isolada e que formava laços entre seus próprios membros que o mesmo expõe posteriormente, já que $75 \%$ dos gobernadores estudados viriam dessa nobreza de serviço.

Um ponto interessante a se destacar na conclusão desse estudo sobre os dados levantados por Molas acerca da duração dos mandatos de homens públicos nos cargos, é que esses demonstram o quanto a naturalidade importava em termos de tempo nos cargos para as Audiencias, estatística que o autor coloca como um movimento geral em todos os âmbitos da administração. Sobre os dados levantados por Dedieu, há um destaque para a variedade de origens dos funcionários públicos, e uma maioria relativa de naturais em comparação com os castelhanos, mas não sobre os não reinícolas (estrangeiros) a ocuparem os cargos de gobernadores e longe de ser uma maioria total.

Dedieu afirma ainda que não havia uma resistência por parte do monarca em apontar naturais a postos em suas regiões, Molas, entretanto, vai diretamente contra 


\section{artigos}

A política das plazas nacionales e a atribuição de ofícios públicos na Catalunha após a Guerra de Sucessão: Uma desnaturalização da administração. essa ideia, exemplificando a atuação direta da Monarquia com o caso de 1747, aludido anteriormente. Ademais, a política das plazas nacionales que Molas aborda não é utilizada pelo historiador francês, deixando em aberto a questão se as indicações de catalães/naturais a gobernadores atendia a uma política semelhante. Com o embasamento utilizado por Molas para introduzir essa política, não podemos deixar de pensar na importância da procedência dos funcionários na indicação de cargos como algo constante e presente em todas as esferas de administração, a falta de comprovação ou contestação por parte de Dedieu sobre essa política para a administração militar, mantém a questão em aberto acerca da aplicação ou não da mesma ou de legislação semelhante sobre essas indicações, mas as proporções apresentadas pelo autor se mostram inegavelmente parecidas com as proporções de funcionários nas Audiencias de Aragão ou de Castela, por exemplo, uma retomada renovada as biografias e documentos oficiais administrativos utilizados com a premissa de procurar uma resposta a essa pergunta se demonstra pertinente para estudos futuros sobre a temática.

\section{Referências Bibliográficas:}

CERRO NARGÁNEZ, Rafael. Els alcaldes majors de Catalunya: entre austriacistes y borbbnics (1717-1725). Barcelona: Estudis Historics i documents dels Arxius de Protocols, NXVI. 1998.

DEDIEU, Jean Pierre. Los gobernadores de Lérida, Barcelona y Gerona en el siglo XVIII. Barcelona: Pedralbes, Revista d'historia moderna. N¹8. 1998. 
Alberto Airton Amendola Gandolfo

DE LA FUENTE, María del Mar Felices, et al. La nobleza titulada en el reinado de Felipe V. Formas de acceso y caracterización. Tesis Doctoral. Universidad de Almería. 2011.

DE LA FUENTE, María del Mar Felices, et al. La nobleza titulada en tiempos de Felipe V. Un balance historiográfico. Revista de historiografía (RevHisto). №24. 2016.

FRANCO RUBIO, Gloria A. ¿Espada o pluma?, ¿destino militar o puesto administrativo? La incorporación de los militares a las instituciones civiles en la España del siglo XVIII. Madrid: Cuadernos de Historia Moderna. № 18. 1997.

FRANCO RUBIO, Gloria A. El ejercicio del poder en la España del siglo XVIII. Entre las prácticas culturales y las prácticas políticas. Madrid: Mélanges de la Casa de Velázquez. $N^{\circ} 35.2005$.

LUZZI TRAFICANTE, Marcelo. Los nuevos títulos nobiliarios durante el reinado de Felipe V. TIEMPOS MODERNOS. vol. 30. 2015.

MOLAS I RIBALTA, Pere. Las Audiencias borbónicas en la Corona de Aragón. In. Historia social de la administración española: estudios sobre los siglos XVII y XVIII. Barcelona: Institución Milá y Fontanals. Departamento de Estudios Medievales. 1980.

TORRAS I RIBÉ, Josep María. La desnaturalización del procedimiento insaculatorio en los municipios aragoneses bajo los Austrias. Salamanca: Studia historica, Historia Moderna. No 15. 1996.

TORRAS I RIBÉ, Josep María. El control polític de les insaculacions del Consell de Cent de Barcelona (1652-1700). Barcelona: Pedralbes, Revista d'historia moderna. N¹3-1. 1993. 


\section{artigos}

A política das plazas nacionales e a atribuição de ofícios públicos na Catalunha após a Guerra de Sucessão: Uma desnaturalização da administração.

VILAR, Pierre. Trad. Manuel Tuñon de Lara. Historia de España. Paris: Librairie espagnole. 1975.

Real Provisión de Madrid. Decreto de 9.X.1715. Nueva Planta de la Real Audiencia del Principado de Cataluña. Estabelecida por Vossa Magestade Felipe V em dezesseis de janeiro de 1716. Barcelona: Impressão Ioseph Texidò. 